\title{
A controlled trial of antihypertensive therapy in systemic sclerosis (scleroderma)
}

\author{
JAMES F. FRIES, CODY W ASNER, JEFFREY BROWN, AND \\ PAUL FEIGENBA UM \\ From the Stanford University School of Medicine, Stanford, California 94305, USA
}

SUMmARY Antihypertensive treatment may be life saving in scleroderma renal crisis. Patients surviving such crises frequently have had dramatic improvement in the dermal manifestations of their scleroderma. To investigate the potential role of antihypertensive treatment in nonhypertensive patients we randomly assigned 28 patients with systemic sclerosis into drug (14) and placebo (14) groups, using blocked randomisation, and followed them up in a prospective, double-blind clinical trial for 24 months. Overall, both groups improved slightly, with both subjective and objective markers. There were no statistically significant differences and no clinically meaningful trends between the 2 groups, except that the blood pressure was reduced in the group on the active drug.

Despite multiple suggested therapies no truly effective treatment for systemic sclerosis (scleroderma) has yet emerged..$^{2}$ Tantalising hints have developed from recent studies emphasising the microvascular pathogenesis of scleroderma ${ }^{34}$ and from our first report $^{5}$ of successful treatment of scleroderma renal crisis with antihypertensive treatment. Both we and others observing patients on dialysis ${ }^{6} 9$ or who have survived renal crisis $^{5}$ have noted dramatic remission of skin disease. These observations fit a theoretical model of vascular pathogenesis, involving microvascular hypertension or a capillary leak syndrome. In this model extrusion of fluid from the microvasculature into tight tissue compartments causes first an oedematous reaction, Raynaud's phenomenon, and telangiectasia, and subsequently leads to intimal sclerosis of small arterioles, distal ischaemic difficulties, and tissue atrophy. ${ }^{34}$ This model has suggested the possibility that antihypertensive treatment might be effective in patients not in renal crisis, and indeed a number of patients have been empirically managed in this way.

To examine the role of antihypertensive treatment in nonhypertensive scleroderma patients we performed a 2-year randomised prospective doubleblind trial comparing alpha-methyl dopa and propranolol versus placebo capsules. Our selection of these 2 antihypertensive agents was principally

Accepted for publication 20 July 1983. Correspondence to Dr J. F. Fries. empirical, these being the agents reported most commonly in anecdotal reports of skin remission following successful treatment of scleroderma renal crisis. $^{.}$

\section{Patients and methods}

Twenty-eight patients with a diagnosis of systemic sclerosis (scleroderma) were asked, with their families, to give informed consent, and after doing so were divided into pairs of patients matched for decade of age, duration of dise ase within 5 years, and disease severity. Randomisation was performed within each pair of patients, one being assigned to the drug and one to the placebo group. A therapist measured the blood pressure on each visit and adjusted the dose of the antihypertensive medications. Another physician, the investigator, blindly assessed clinical results at $0,6,12,18$ and 24 months. The investigator was blind to the drugs given, to the laboratory values, to the blood pressure recordings, and to any therapeutic adjustments which might have been performed by the therapist, who was also blind to the particular drug. The dependent variables consisted of a skin map of involved areas, photographs of hand and face, haematocrit (packed cell volume), serum creatinine, disability index, finger-to-palm distance, interincisor distance, physician's overall impression, and patient's overall impression. Power calculations suggested that there were too few patients in the study to make a definitive result likely. 
Table 1 Patient drop-outs

\begin{tabular}{|c|c|c|}
\hline Time in study & Active or placebo & Reason for dropping out \\
\hline 18 Months & Active drug & $\begin{array}{l}\text { Deceased (10 December } 1980) \text {. } \\
\text { Pulmonary fibrosis with congestive heart failure }\end{array}$ \\
\hline 8 Weeks & Placebo drug & General ill feeling; patient desired to drop out \\
\hline 4 Weeks & Placebo drug & Misdiagnosed (morphoea) \\
\hline 12 Months & Active drug & Nausea, dizziness, diarrhoea \\
\hline 18 Months & Placebo drug & $\begin{array}{l}\text { Began taking prednisone, cyclophosphamide, } \\
\text { and undergoing plasmapheresis under care of own } \\
\text { physician }\end{array}$ \\
\hline 6 Months & Active drug & No improvement in disease; patient desired to drop out \\
\hline 16 Weeks & Active drug & Dizziness \\
\hline 12 Weeks & Active drug & Diarrhoea \\
\hline 2 Weeks & Placebo drug & Severe rash \\
\hline
\end{tabular}

Hence the study was designed to seek trends and observations which would justify a larger and more definitive study of these or similar therapeutic agents. Drug dosages were begun at low levels, and increased to full dosage at 12 weeks, this dose being $320 \mathrm{mg}$ of propranolol and $1000 \mathrm{mg}$ of alpha-methyl dopa daily. Placebo patients received matched medications with an identical schedule of administration. The patients could not be on prednisone, immunosuppressants, or colchicine during the study. They were seen at $0,2,4$, 6,8 , and 12 weeks, and at $6,9,12,15,18,21$, and 24 months.

\section{Results}

Nineteen patients completed the 2-year study; 9 dropped out (Table 1). Six of the drop-outs were on active drug regimens and discontinued the study because of side effects such as diarrhoea, dizziness, or nausea in 4 instances. lack of improvement in condition in one instance, and by death of a patient with extremely severe pulmonary fibrosis and congestive heart failure at entry to the study. The patient was removed from the study 3 months before death because of worsening pulmonary status, and autopsy revealed death due to extensive pulmonary fibrosis. Three patients on placebo dropped out the study, one because of recognition of a misdiagnosis, one underwent other treatment not allowed by the protocol, and one complained of severe rash. The study drugs were well tolerated by other patients, although Coombs positivity, without haemolytic anaemia, developed in 7 of 8 patients on drug regimens.

Blocked randomisation resulted in initially quite

Table 2 Summary of findings: mean values

\begin{tabular}{|c|c|c|c|c|c|c|}
\hline & \multicolumn{3}{|c|}{$\begin{array}{l}\text { Active drugs } \\
\text { (8) }\end{array}$} & \multicolumn{3}{|l|}{$\begin{array}{l}\text { Placebo } \\
\text { (11) }\end{array}$} \\
\hline & Initial & Final & Difference & Initial & Final & Difference \\
\hline $\begin{array}{l}\text { Diastolic blood pressure }(\mathrm{mmHg})^{*} \\
\text { Finger-to-distal palmar crease }(\mathrm{mm})\end{array}$ & 87 & 74 & -13 & 82 & 83 & +1 \\
\hline Right & 16 & 15 & -1 & 30 & 22 & -6 \\
\hline Left & 18 & 17 & -1 & 30 & 22 & -8 \\
\hline Interincisor distance (mm) & 34 & 36 & +2 & 33 & 34 & \\
\hline $\begin{array}{l}\text { Disability index (HAQ) (mm) } \\
\text { Patient's impression (1-5, worse }\end{array}$ & $0 \cdot 68$ & 0.65 & $-0 \cdot 03$ & 0.78 & 0.67 & $-0 \cdot 11$ \\
\hline $\begin{array}{l}\text { to better) } \\
\text { Physician's impression (1-5, Worse }\end{array}$ & $2 \cdot 75$ & $3 \cdot 13$ & $+0 \cdot 38$ & 3.09 & $3 \cdot 0$ & -0.09 \\
\hline $\begin{array}{l}\text { to better) } \\
\text { Creatinine }(\mathrm{mg} / \mathrm{dl})\end{array}$ & $\begin{array}{l}3 \cdot 0 \\
0 \cdot 85\end{array}$ & $\begin{array}{l}3 \cdot 25 \\
0 \cdot 925\end{array}$ & $\begin{array}{l}+0.25 \\
+0.075\end{array}$ & $\begin{array}{l}3.09 \\
0 \cdot 80\end{array}$ & $\begin{array}{l}3.09 \\
0 \cdot 85\end{array}$ & $\begin{array}{l}0 \\
+0.05\end{array}$ \\
\hline
\end{tabular}

$* \mathrm{p}<0.01$.

SI conversion: creatinine $\mathrm{mg} / \mathrm{dl} \times 88 \cdot 4=\mu \mathrm{mol} / \mathrm{l}$. 
Table 3 Summary of findings: number of patients

\begin{tabular}{|c|c|c|c|c|c|c|}
\hline & \multicolumn{3}{|c|}{$\begin{array}{l}\text { Active drugs } \\
\text { (8) }\end{array}$} & \multicolumn{3}{|l|}{$\begin{array}{l}\text { Placebo } \\
\text { (11) }\end{array}$} \\
\hline & Improved & Same & Worse & Improved & Same & Worse \\
\hline Blood pressure (diastolic) & 6 & 0 & 2 & 4 & 1 & 6 \\
\hline $\begin{array}{l}\text { Finger-to-distal palmar crease } \\
\text { Right }\end{array}$ & \multicolumn{6}{|c|}{ Finger-to-distal palmar crease } \\
\hline Left & 4 & 1 & 2 & $\begin{array}{l}0 \\
6\end{array}$ & $\begin{array}{l}0 \\
1\end{array}$ & $\begin{array}{l}4 \\
1\end{array}$ \\
\hline Interincisor distance & 6 & 0 & 2 & 4 & 1 & 6 \\
\hline Disability index & 4 & 2 & 2 & 6 & 3 & 2 \\
\hline Patient's impression & 2 & 6 & 0 & 2 & 6 & 3 \\
\hline Physician's impression & 1 & 7 & 0 & 2 & 7 & 2 \\
\hline Creatinine & 1 & 0 & 7 & 3 & 3 & 5 \\
\hline
\end{tabular}

comparable patient groups. A male to female ratio of 13:1 was matched in each group, and the mean age was 49.2 and 49.6 , and mean duration 6.8 and 6.5 years, in the drug and placebo groups respectively. Even among those completing the study and included in the analysis the initial values, as shown in Table 2 , were quite similar between groups. Since more drop-outs occurred in the active drug group, the placebo group retained a slightly more seriously affected group of individuals, creating a slight bias in favour of the group on active drug.

Table 2 summarises the initial and final findings of the major dependent variables. The mean diastolic blood pressure was $14 \mathrm{mmHg}$ different, the active drug group having declined by $13 \mathrm{mmHg}$ while the placebo group increased by 1 . This difference was clinically and statistically significant (Wilcoxon rank sum test on the differences between initial and final values, $\mathrm{p}<0.05$ ), as was systolic blood pressure. Of the remaining variables no statistically significant results were obtained. Finger-to-distal-palmarcrease measurements and disability index ${ }^{10}$ showed a trend toward the placebo, while interincisor distance, patients' and physicians' impressions, and serum creatinine showed a slight trend toward the active drug. None of these trends were clinically important.

Table 3 summarises the number of patients improved, the same, or worse on the active drug or placebo regimens. Again, there were no statistically significant differences. The trend favoured placebo in

Table 4 Disability scores over time

\begin{tabular}{lccccc}
\hline & $0 M o$ & $6 M o$ & $12 M o$ & $18 M o$ & $24 M o$ \\
\hline Active drugs (8) & 0.68 & 0.43 & 0.53 & 0.55 & 0.65 \\
Placebo (11) & 0.78 & 0.62 & 0.59 & 0.65 & 0.58 \\
Combined (19) & 0.73 & 0.53 & 0.56 & 0.60 & 0.72 \\
\hline
\end{tabular}

Mo=month. finger-to-distal-palmar-crease measurements on the left, and in the disability index scores, and favoured the active drug group in the other parameters. However, no clinically or statistically significant findings were present.

Table 4 shows progression of disability scores over time. We present these data to indicate the slow progression of disability in scleroderma, and the positive direction of changes in the early months of a trial. This same trend was observed among physicians' observations such as finger-to-palm distance and interincisor distance.

\section{Discussion}

This was an informative study in terms of the natural history of scleroderma and in terms of experimental design for studies of treatment affecting scleroderma, although disappointing in terms of finding an effective treatment for this disease. Overall, both groups improved slightly, with both subjective and objective markers. There were no statistically significant differences and no clinically meaningful trends between the 2 groups, except for blood pressure, which was reduced in the group on antihypertensive drug.

The study demonstrates a favourable natural history of scleroderma over the medium term of 2 years. We believe that this suggests a positive effect of inclusion in a study of patients with an 'untreatable' disease. There is a large and objective placebo effect, and this effect carries over into the patient's disability and into objective measures of disease. This phenomenon has been previously observed in studies of intra-articular saline, which proves remarkably effective (as effective as intra-arterial reserpine) in the healing of scleroderma skin ulcers and the minimisation of symptoms due to Raynaud's phenomenon. ${ }^{11}$ It suggests that therapeutic benefit may be afforded by relatively frequent and 'positive' visits of the patient to an understanding physician. 
The study design worked well. A randomised controlled trial can be performed successfully in progressive systemic sclerosis, despite difficulties in precision of endpoints and the necessity for a long period of observation. Better dependent variables should be sought; these might include the total skin score recommended by Medsger et $a .^{2}{ }^{2}$ and perhaps an observation of hair regrowth on forearms, which appeared to us to be a sensitive index of which patients were doing well during this study.

Randomised controlled trials in scleroderma will require 50 to 100 patients in each group to provide definitive results. Additionally, patient selection should emphasise individuals with reversible lesions. Patients with end-stage scleroderma who are unlikely to respond should be excluded, as should patients with the CREST syndrome, which is likely to be nonprogressive in any event over an extended period of time. We did not exclude such patients, and thus only approximately half of our patients were ideal candidates for this type of study. The requirement for careful patient selection and for large numbers suggests the need for multicentre trials.

We conclude that antihypertensive treatment is not clinically effective in managing the dermal manifestations of scleroderma. We find no indications for further study of these particular drugs. Could we have missed an effect? We do not believe that higher doses could have been used, since drop-outs were already excessive in the drug group. We believe that adverse chance could have caused us to miss an effect in a small study, particularly since some patients enrolled might not have been able to change. On the other hand the absence of any kind of a trend, even though drop-outs biased the study in favour of the active drug, suggests that no large and frequent response has been missed. There were 4 particularly impressive 'responses', 2 in the drug and 2 in the placebo group.

We doubt whether selection of other antihypertensive agents, such as captopril, would have made a difference. Interestingly, despite assertions ${ }^{11213}$ that it is captopril and similar drugs which have allowed successful treatment of renal crisis in scleroderma, this is not the case. The first patients surviving scleroderma renal crisis, ${ }^{5}$ and the majority of patients surviving since, have been managed with traditional antihypertensive regimens. There is no evidence to suggest that the frequency of successful treatment ( 7 out of 13 in our hands with standard agents) is any different with captopril or other agents. Similarly the majority of reported dermal remissions have occur- red with drugs other than captopril. It seems highly likely that reduction of blood pressure to low normal levels ${ }^{414}$ is the common denominator in successful antihypertensive treatment of scleroderma renal crisis, as it is with ordinary malignant hypertension, and that the newer agents have merit only to the degree that they may on occasion prove to be more effective at blood pressure reduction. This study was based on the observation of dermal remission after alpha-methyl dopa and propranolol maintenance of patients in scleroderma renal crisis for up to 12 years. Nonhypertensive patients do not appear to undergo dermal remission with these drugs.

This work was supported by grants from the Northern California chapter of the Arthritis Foundation and by a grant from the National Institutes of Health to ARAMIS, the American Rheumatism Association Medical Information System. Drugs and placebos were kindly supplied by the manufacturers, Ayerst Laboratories and Merck Laboratories.

We are most grateful for study co-ordination by Connie Hartnett and Pat Spitz. We appreciate the biostatistical assistance of Donald Y. Young.

\section{References}

1 Gershwin M E. Slow progress with scleroderma. Ann Intern Med 1982; 97: 776-8.

2 Steen VD, Medsger T A, Redman G P. D-penicillamine therapy in progressive systemic sclerosis (scleroderma). Ann Intern Med 1982; 97: 652-9.

3 Campbell P M, LeRoy E C. Pathogenesis of systemic sclerosis: a vascular hypothesis. Semin Arthritis Rheum 1975; 4: 351-68.

4 Fries J F. The microvascular pathogenesis of scleroderma: an hypothesis. Ann Intern Med 1979; 91: 788-9.

5 Wasner C, Cooke C R, Fries J F. Successful medical treatment of scleroderma renal crisis. $N$ Engl J Med 1978; 299: 873-5.

6 Barker D J, Farr M J. Resolution of cutaneous manifestations of systemic sclerosis after haemodialysis. Br Med J 1976; i: 501.

7 LeRoy E C, Fleischmann R M. The management of renal scleroderma: experience with dialysis, nephrectomy and transplantation. Am J Med 1978; 64: 974-8.

8 Rodnan G P. Hemodialysis and kidney transplantation for renal failure from scleroderma (discussion). Arthritis Rheum 1973; 16: 268-9.

9 Richardson J A. Hemodialysis and kidney transplantation for renal failure from scleroderma. Arthritis Rheum 1973; 16: 265-71.

10 Fries J F, Spitz P W, Kraines R G, Holman H R. Measurement of patient outcome in arthritis. Arthritis Rheum 1980; 23: 137-45.

11 Siegel R C, Fries J F. Intra-arterially administered reserpine and saline in scleroderma. Arch Intern Med 1974; 134: 515-8.

12 Whitman H H. Variable response to oral converting enzyme blockade in hypertensive scleroderma patients. Arthritis Rheum 1980; 23: 763-9.

13 Lopez-Ovejero J A, Saal S D, D'Angelo W A, Cleigh J S, Stenzel $\mathbf{K} \mathbf{H}$, Laragh $\mathbf{J} \mathbf{H}$. Reversal of vascular and renal crisis of scleroderma by oral angiotensin-converting enzyme blockade. $N$ Engl J Med 1979; 300: 1417-9.

14 Gavras H, Gavras I, Cannon P, et al. Is elevated plasma renin activity of prognostic importance in progressive systemic sclerosis? Arch Intern Med 1977; 137: 1554-8. 